\begin{tabular}{|c|c|c|}
\hline $\begin{array}{l}\text { PKS } \\
\begin{array}{l}\text { PULLII } \\
\text { KNOWLEDGE }\end{array} \\
\text { PROIECT }\end{array}$ & $\begin{array}{c}\text { REVISTA DE GEOGRAFIA } \\
\text { (RECIFE) } \\
\text { http://www.revista.ufpe.br/revistageografiai }\end{array}$ & $\frac{\text { OJS }}{\text { OPEN }}$ \\
\hline
\end{tabular}

\title{
GEOMORFOLOGIA E SUA RELAÇÃO COM A CONFIGURAÇÃO ESPACIAL DO MUNICÍPIO DE MACHADINHO D'OESTE NO ESTADO DE RONDÔNIA - SUDOESTE DA AMAZÔNIA
}

\author{
Fabiana Barbosa Gomes ${ }^{1}$, Alexis Bastos ${ }^{2}$ \\ ${ }^{1}$ Centro de Estudos da Cultura e do Meio Ambiente da Amazonia, Email:fabiana@rioterra.org.br \\ ${ }^{2}$ Centro de Estudos da Cultura e do Meio Ambiente da Amazonia, Email: alexis@rioterra.org.br
}

Artigo recebido em 10/12/2017 e aceito em 09/03/2018

\begin{abstract}
RESUMO
O trabalho ora apresentado tem como objetivo analisar as unidades geomorfológicas do município de Machadinho d'Oeste, Rondônia e relacioná-la aos modos de ocupação e arranjos espaciais estabelecidos por meio de intervenção governamental. Para o desenvolvimento da pesquisa foram realizados levantamentos de dados secundários da área e empregadas técnicas de geoprocessamento para análise dos dados. Projetos de assentamentos e unidades de conservação dispostas lado a lado, compõem um verdadeiro mosaico no município. Estes espaços encontram-se estabelecidos sobre diferentes unidades de relevo e desempenham funções díspares quanto ao uso do solo. Verificou-se que o intensivo uso dos solos na área, principalmente nos assentamentos ou ainda nas propriedades rurais particulares tem originado mudanças nas características do ambiente, ocasionando condições de limitações marcantes para uso agrícola e favorecendo o avanço do desmatamento para proximidade das áreas protegidas.
\end{abstract}

Palavras-chave: Geomorfologia; uso e ocupação do solo; Região Amazônica

\section{GEOMORPHOLOGY AND ITS RELATION WITH THE SPATIAL CONFIGURATION OF THE MUNICIPALITY OF MACHADINHO D'OESTE IN THE STATE OF RONDÔNIA - SOUTHWEST OF THE AMAZON}

\begin{abstract}
The work presented were conducted in order to analyze the geomorphological units sited in Machadinho d'Oeste municipality, Rondônia and relate it to the occupation modes and spatial arrangements established according governmental intervention. The research development was carried out based on the area secondary data and geoprocessing techniques for data analysis. Settlement projects and conservation units arranged side by side, constitute a mosaic in the municipality. These spaces are established on different relief units and perform very different functions regarding land use. It was verified that the intensive use of the soils in the area, mainly in the settlements or even in the private farms, has caused changes on the environment characteristic's, causing significant limitations for agricultural use and favoring deforestation advance to protected areas limits.
\end{abstract}

Key-words: Geomorphology; land use and soil occupation; Amazon Region. 


\section{INTRODUÇÃO}

Aspectos relacionados a geomorfologia são de fundamental importância para questões relativas ao uso e ocupação dos solos. Observar tais aspectos na paisagem permite não apenas identificar áreas mais adequadas à ocupação, mas também definir aquelas que reúnem condições singulares para a conservação de recursos naturais.

As limitações do meio físico, capacidade de suporte dos ambientes e aptidão agrícola nunca foram os principais indiciadores de qualidade de ambiente considerados pelos sucessivos governos para a definição de áreas onde assentar os inúmeros grupos de migrantes. Mesmo cientes das limitações ambientais, sucessivos governos mantiveram as políticas de atração das populações para o estado de Rondônia (BECKER, 1998).

Machadinho foi palco da instalação dos primeiros assentamentos criados pelo governo federal nas décadas de 80 e 90 para abrigar os contingentes de trabalhadores rurais sem terras dos estados do sul e sudeste (MATTOS \& YOUNG, 1991; MIRANDA et al. 1997). O Projeto de Assentamento Machadinho d' Oeste foi criado em 1980 e implantado em 1982 através do POLONOROESTE - Programa Integrado de Desenvolvimento do Noroeste do Brasil. Em função dos estudos pedológicos e topográficos previamente realizados, o projeto de Machadinho d'Oeste tentou inovou no desenho de sua grade de propriedades. Enquanto a maioria dos assentamentos rurais de Rondônia foi implantada seguindo o modelo "espinha de peixe", no projeto Machadinho a criação dos lotes e das estradas no início, procurou acompanhar sempre que possível a topografia.

Além disso, o projeto também incluiu as reservas florestais agrupadas, dispostas em blocos, que posteriormente foram decretadas como Reservas Extrativistas Estaduais (BATISTTELA \& BRONDIZIO, 2001). Na sequência da política de colonização da Amazônia, novos projetos foram implantados pelo INCRA, e, a partir do ano de 1995, o município teve a participação em mais 13 outros projetos de assentamentos. Atualmente, o município possui uma configuração espacial composta por área urbana, diversos assentamentos, unidades de conservação federais e estaduais, onde atividades econômicas estão voltadas principalmente para a agricultura, pecuária e extração de madeira. 
Este trabalho teve como foco principal desenvolver um olhar sobre as características geomorfológicas do município associando estas informações com a distribuição espacial das unidades de conservação e projetos de assentamento, bem como as questões de uso e ocupação dos solos. Assim, uma breve caracterização de outros elementos do meio físico e de seu modo de ocupação serão abordados afim de apoiar o leitor a entender o lugar. Machadinho d'Oeste localiza-se no extremo norte do estado de Rondônia, no sudoeste da Amazônia.

A região do município possui o clima do tipo Aw (quente e úmido), apresentando precipitação elevada, com média anual dividida em seis faixas diferentes, que oscilam de 2100 a 2600 mm/ano (GAMA, 2002). Em termos de evolução da paisagem, abrange unidades de diferentes eras e períodos da história no tempo geológico, remonta desde o Paleoproterozoico até o mais recente. Está situado na unidade morfoescultural Escudo Brasil Central, cujo embasamento é constituído por Suítes intrusivas e metamórficas Paleoproterozoicas sobrepostas por coberturas plataformais Paleo e Neoproterozoicas, fazendo limite com a unidade morfoescultural Bacia Sedimentar Amazônica (QUADROS \& RIZZOTTO, 2007; QUADROS, 2011).

A análise regional das formas de relevo distribuídas no estado, interpretado no âmbito do estado de Rondônia (RONDÔNIA, 2002), indica a existência de cinco ambientes geomorfológicos: 1) áreas de domínio de superfícies regionais de aplanamento que são divididas em três níveis I, II e III; 2) serras constituídas por rochas sedimentares antigas na forma de superfícies tabulares; 3) áreas de denudação em rochas sedimentares terciárias; 4) colinas e morros associados à presença de rochas resistentes à erosão; 5) o sistema fluvial do rio Madeira.

\section{MATERIAL E MÉTODOS}

Para o desenvolvimento do trabalho foi realizado levantamento do histórico de ocupação do município de Machadinho D’Oeste por meio de bibliografias disponíveis, incluindo o acervo de instituições públicas. Para compor a base de dados do meio físico e elaboração dos mapas temáticos foram utilizados dados em formato shapefile do PLANAFLORO SEDAM/RO (2002), assim como dados do INCRA (2010), IBGE (2006) e ICMBio (2016).

Para confecção dos mapas temáticos e posterior sobreposições para as análises, utilizou-se o software ArcGIS 10.2. Os mapas temáticos gerados foram de 
Geomorfologia, de Geologia, de Solos, de Vegetação, de Unidades de Conservação e de Projetos de Assentamento. Com estas informações foi possível examinar em que condições do relevo os Projetos de Assentamentos e Unidades de Conservação foram criados. Imagens do satélite Landsat L8 do ano de 2015, cenas 231-66 e 231- 67 foram incorporadas na análise para a avaliação da evolução e dinâmica de ocupação ao longo dos anos, bem como na detecção e definição das áreas desmatadas.

O método aplicado foi o de interpretação visual da imagem de satélite (FLOREZANO, 2002). Após este procedimento, sobreposições com os dados temáticos (geomorfologia, Unidades de Conservação e de Projetos de Assentamento) e as imagens foram realizadas para melhor compreensão espacial das áreas em transformação. Posteriormente realizou-se campanha de campo, com enfoque na validação das informações dos mapas e verificação dos tipos de usos do solo.

\section{RESULTADOS E DISCUSSÕES}

O contexto geomorfológico do município de Machadinho d'Oeste, interpretado no âmbito do estado de Rondônia (RONDÔNIA, 2002), revela características morfológicas relacionadas às categorias de agradação (unidades deposicionais ou agradacionais) e degradação (unidades denudacionais), sendo a maior parte do município representada pelas superfícies de aplainamento. E é nas áreas onde se encontram as unidades denudacionais que se constata a instalação da maior parte dos projetos de assentamentos no município, e a posterior intensificação da ocupação nesta área (Figura 1A).

Nesta categoria estão às formas de relevo elaboradas por processos de denudação que são responsáveis pelo seu rebaixamento progressivo do terreno. Na região as unidades denudacionais encontradas são as superfícies de aplanamento situadas em dois níveis de dissecação, com diferenças quanto ao grau de dissecação e a intensidade de presença ou não de formas de relevos residuais, como inselbergs e tors. 
Figura 1 - Mapa de Geomorfologia. (A) Projetos de Assentamento. (B) Unidades de Conservação. Fonte: Os autores.

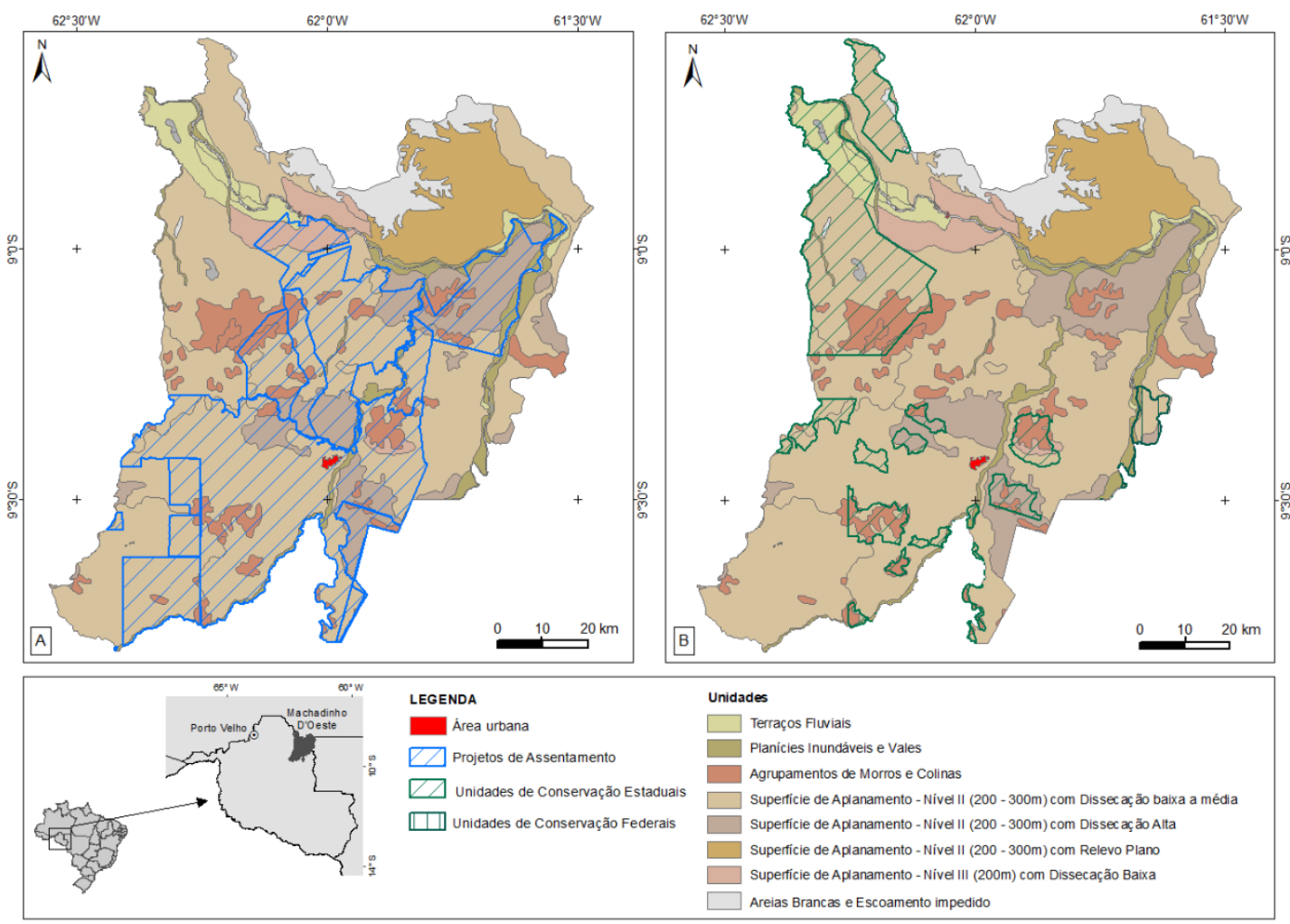

O nível III ocorre em cotas inferiores a 200 m e apresentam densidade variável de inselbergs e tors. O nível II (200-300 m), abrange a maior parte da área do município, e por consequência a maioria dos projetos de assentamentos estão presentes. Este nível ocorre sobre rochas do embasamento cristalino e as cotas atingidas por esta superfície distribuem-se no intervalo de 200-300m. Nesta unidade ocorrem os latossolos, considerados solos profundos, de baixa fertilidade natural e fortemente ácidos. Outro ponto em destaque nessas áreas são os níveis de dissecação que variam de baixa a alta, mas sendo o fator determinante a ausência ou presença esporádicas de inselbergs e tors.

Em meio às superfícies de aplanamento do nível II estão os Agrupamentos de morros e colinas, que ocorrem de forma dispersa regionalmente, como relevos residuais, associados a diferentes rochas do embasamento cristalino, não possuindo controle estrutural nítido. Estão presentes principalmente na área onde ocorrem os granitos de Rondônia e a suíte intrusiva Serra da Providência. Em parte dessas áreas o governo instituiu diversas unidades de conservação (Figura 1B). 
Na década de 1990 foram destinadas áreas para a constituição de 18 unidades de conservação estaduais, onde quinze delas foram originadas a partir de áreas de antigas Reservas Florestais criadas em blocos no Projeto de Assentamento Machadinho (RONDÔNIA, 2002). São unidades divididas em dois grupos com características específicas, são eles: Unidades de Proteção Integral, onde é admitido apenas o uso indireto dos seus recursos naturais e Unidades de Uso Sustentável, que tem como objetivo compatibilizar a conservação da natureza com o uso sustentável de parcela dos seus recursos naturais (MMA, 2004).

O tipo de Unidade de Conservação em maior número em Machadinho d'Oeste são as Reservas Extrativistas, possuem populações tradicionais, que utilizam de forma sustentável a terra, praticando um modelo de uso bem diferente do que se observa no entorno dessas áreas. Posteriormente, a área onde está a unidade das areias brancas, na porção norte do município, veio compor o Parque Nacional Campos Amazônicos e a Reserva Biológica Jaru, ambas como unidades de conservação federal.

As Areias Brancas e Escoamento Impedido estão representadas por extensas superfícies arenosas, refletindo uma coloração esbranquiçada e sendo um produto residual do intemperismo químico sobre formações mais antigas. Foram depressões inseridas em contexto de superfícies de aplanamento e por isso o escoamento das águas é dificultado. Essa unidade predominantemente comporta vegetação do tipo savana e está localizada na margem do rio Machado, sendo seus níveis de altitudes ainda mais baixos do que a média da área em análise, conforme Gomes (2009).

As áreas onde se encontram as demais propriedades rurais exibem diversidade maior na composição do relevo, ora apresentam um relevo um pouco mais ondulado, com presença de agrupamentos de morros e colinas, alguns com controle estrutural, áreas das unidades denudacionais com diferentes níveis de dissecação e na presença de muitos tors e inselbergs, e as áreas de terraços, áreas alagadas, lagos, planícies inundáveis e as áreas de escoamento impedido.

$\mathrm{Na}$ análise da dinâmica da ocupação da área, verifica-se que incialmente a prática adotada é o desmatamento para a chamada benfeitoria do lote, já exercendo o desmatamento sua parcela na modificação do ambiente, em seguida ocorre o plantio das culturas nos solos, no caso de Machadinho d'Oeste, no solo do tipo latossolos, que apesar de ter certa estabilidade quanto à erosão, possui limitação ao uso agrícola pela baixa fertilidade natural, além de serem fortemente ácidos. 
Após o plantio e a não adoção de práticas de conservação do solo, passados alguns anos esse solo perde suas propriedades naturais, seus nutrientes e minerais, tornando-se mais pobres e expondo mais limitações (GONÇALVES, 2002; EMBRAPA, 2009). Como sequência deste processo, vem a baixa produtividade que modifica a qualidade das plantas e da produção. Assim, o produtor parte para o uso novas áreas do seu lote onde os solos ainda não foram alterados ou até mesmo utilizam as áreas protegidas por lei como a Reserva Legal e APP - Áreas de Preservação Permanente, e em casos extremos a ocupação das unidades de conservação. Desta forma, os atuais processos de ocupação começam a se instalar sobre áreas onde ambiente apresenta uma fragilidade maior (áreas de planícies, terraços fluviais e morros e colinas).

A atividade da pecuária na região tem se intensificado, expressiva no estado, ela também faz parte das causas do desmatamento e contribui para os processos de degradação do solo em Machadinho d'Oeste. O escoamento e a erosão sob pastos são consequências da compactação do solo causada pela exposição ao sol e o pisotear das patas do gado (Fearnside, 1989). Apesar de alguns projetos de assentamento do município como o PA Machadinho tentarem distribuir os lotes de maneira mais adequada à área, somente essa medida não garante o desenvolvimento para as propriedades, uma boa produção e nem a manutenção do meio ambiente.

Como exposto, juntamente aos processos de ocupação da Amazônia vêm os problemas relacionados ao desmatamento, e a dinâmica desse processo em Machadinho d'Oeste iniciou-se com a implantação de assentamentos, seguido pelo desmatamento das áreas, posteriormente a implantação de culturas e pastagem. Conforme observado em Gomes, (2009) estas pastagens muitas vezes instaladas em terrenos mais ondulosos e colinosos onde a rampa de declive é mais acentuada, combinado com a baixa agregação dos elementos encontrados nos solos, contribui para a atuação da erosão laminar que além da retirada dos nutrientes do solo, viabiliza a erosão linear, evoluindo para ravinas e processo e escalonamento, causando ainda o assoreamento dos rios (Figura 2 e Figura 3). 
Figura 2 - Área com processo erosivo (pastagem em relevo ondulado com processo de escalonamento). Fonte: Os autores.

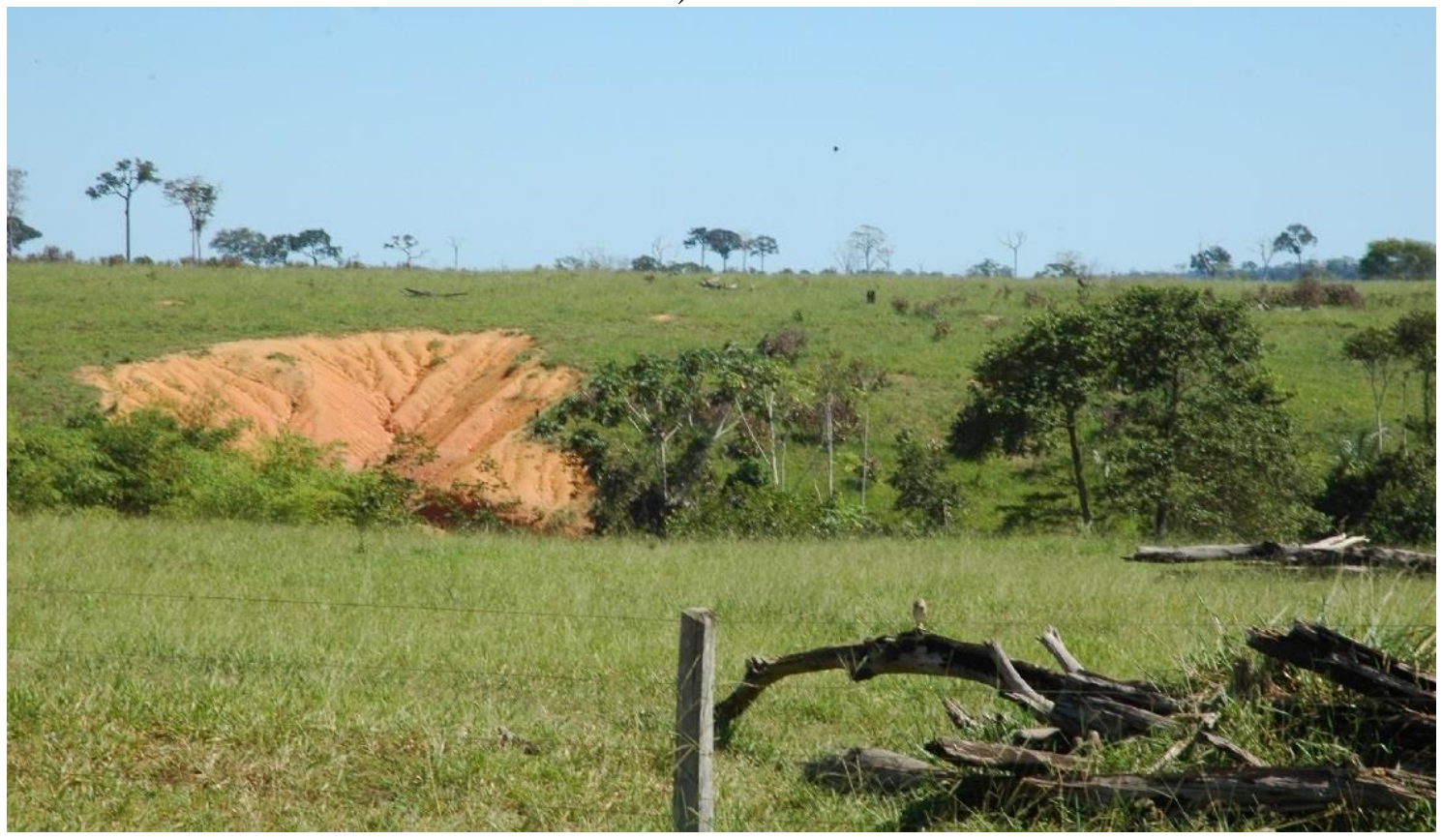

Figura 3 - Processo erosivo e assoreamento de rio. Fonte: Os autores.

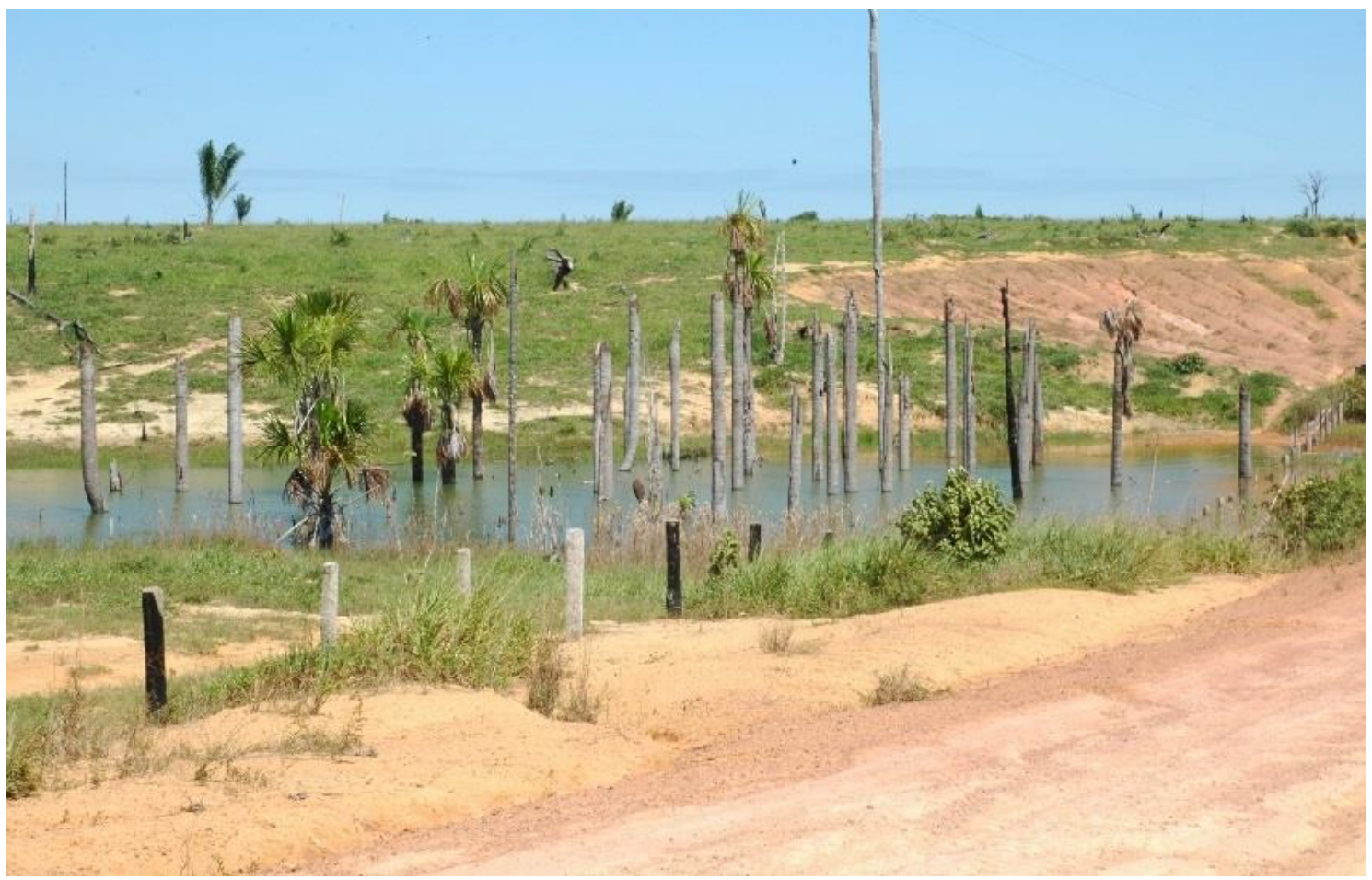

Como a densidade da vegetação nestes terrenos é uma das defesas naturais contra a erosão, a retirada desta cobertura e a aplicação de outros usos sem a adoção de práticas adequadas podem ocasionar diferentes formas de degradação para a paisagem. A ocupação do município, como verificado nas figuras $4 \mathrm{~A}$ e $4 \mathrm{~B}$ demonstra que o 
desmatamento e a conversão da vegetação para usos agropecuários se concentram majoritariamente nos limites das áreas dos Projetos de Assentamentos.

Figura 4 - Carta imagem da área do Município de Machadinho d'Oeste. (A) Projetos de Assentamento. (B) Unidades de Conservação. Fonte: Os autores.

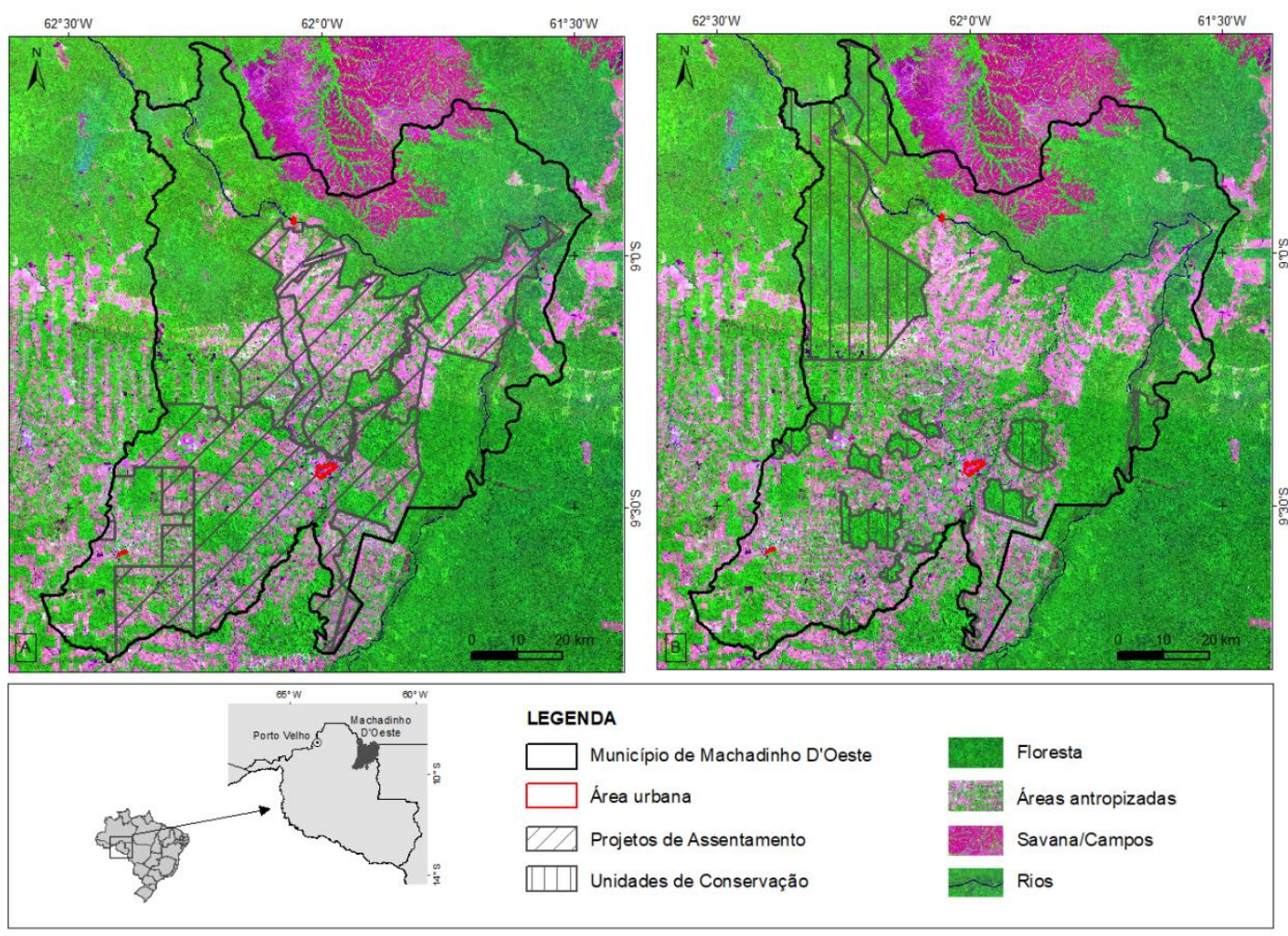

São áreas onde cada vez mais são abertas estradas sem o planejamento. Por outro lado, as áreas demarcadas como Unidades de Conservação ainda abrigam vegetação nativa. Contudo, as unidades estaduais situadas em meio aos projetos de assentamento têm seus limites marcados por intensa pressão pelos recursos naturais que ainda possui. Os processos de pressão antrópica vêm se tornando cada vez mais intenso, atualmente no estado de Rondônia, as unidades de conservação vem sofrendo com essa pressão sobre novas áreas para a exploração dos recursos naturais, várias unidades possuem estradas dentro de seus limites (SAWYER, 2001; RIBEIRO et al. 2005; GTA, 2008). 


\section{CONSIDERAÇÕES FINAIS}

A ocupação do município de Machadinho d'Oeste influenciou de forma decisiva a sua configuração territorial e está relacionada com os usos do solo, onde há interferência direta com suas unidades de paisagem natural e capacidade de suporte de seus recursos naturais.

A instalação dos projetos de assentamentos e a posterior intensificação da ocupação no município de Machadinho d'Oeste ocorreram preferencialmente nas áreas onde se encontram as unidades denudacionais. A maior parte da área onde o relevo apresenta-se mais ondulado, com presença de agrupamentos de morros e colinas estão instituídas diversas unidades de conservação estaduais e federais.

Destacamos como ponto positivo a existência de unidades de conservação tanto federais como estaduais. Estas são responsáveis localmente, por conter novas frentes de desmatamento, por assegurar que rios tenham suas zonas de recarga conservadas, que são importantes para manutenção do equilíbrio ambiental local. A manutenção das unidades de paisagens naturais é necessária, e devem ser conservadas de maneira que possam garantir que os processos naturais continuem se auto regulando e se ajustando.

\section{AGRADECIMENTOS}

Agradecemos o apoio financeiro do Banco Nacional de Desenvolvimento Econômico e Social - BNDES através do Fundo Amazônia. Os autores agradecem ainda, ao Centro de Estudos Rioterra, ao Grupo de Pesquisa Geociências - UNIR, ao ICMBio - PARNA Campos Amazônicos, por todo o apoio e contribuição à pesquisa.

\section{REFERÊNCIAS BIBLIOGRÁFICAS}

BATISTELLA, M.; BRONDIZIO, E. Uma estratégia integrada de análise e monitoramento de assentamentos rurais na Amazônia. In: GIS BRASIL 2001: SHOW DE GEOTECNOLOGIAS, 7., Curitiba. Anais... Curitiba: FatorGis-Selper, 2001. Disponível em: <http://www.gisbrasil.com.br>. Acesso em: 26 jul. 2001. BECKER, B. K. Amazônia. Ática: São Paulo, 1998. EMBRAPA. Sustentabilidade agrícola na Amazônia. 23 anos de monitoramento da agricultura em Machadinho d'Oeste. Campinas: Embrapa Monitoramento por Satélite, 
2009. Disponível em: http://www.machadinho.cnpm.embrapa.br/. Acesso em 21 de junho de 2009.

FEARNSIDE, P. M. A ocupação humana de Rondônia: impactos, limites e planejamento. Brasília: Assessoria Editorial e Divulgação Científica, 1989. 76p. FLORENZANO, T.G. Imagens de satélite para estudos ambientais. São Paulo, Oficina de Textos, 2002. GONÇALVES, F.R.L. Conservação dos solos. In: Conservação e cultivo dos solos para $\begin{array}{lllll}\text { plantações } & \text { tropicais. } & \text { Piracicaba-SP, } & \text { IPEF, }\end{array}$ GOMES, F.B. Modos de ocupação no município de Machadinho d'Oeste/RO e suas relações com o equilíbrio natural da paisagem e ajustes morfodinâmicos. Dissertação, Universidade Federal de Rondônia, Porto Velho, UNIR, 2009. GAMA, M.J. Clima. In: Atlas geoambiental de Rondônia. Porto Velho, SEDAM, 2002. GTA. Grupo de Trabalho Amazônico. O Fim da Floresta? A devastação das Unidades de Conservação e Terras Indígenas no Estado de Rondônia, 2008. ICMBio. Instituto Chico Mendes. Mapa temático e dados geoestatísticos. Unidades de Conservação. Disponível em: <http://www.icmbio.gov.br/portal/geoprocessamentos/51menu-servicos/4004-downloads-mapa-tematico-e-dados-geoestatisticos-das-uc-s >. Acesso em: 12 ago. 2016.

IBGE - Instituto Brasileiro de Geografia e Estatística. Informações Ambientais Vegetação, 2006. Disponível em: <http:// http://downloads.ibge.gov.br/downloads_geociencias.htm>. Acesso em: 05 nov. 2016. INCRA - Instituto Nacional de Colonização e Reforma Agrária. Acervo Fundiário 2010. Disponível em: <http:// http://acervofundiario.incra.gov.br/i3geo/interface/incra.htm>. Acesso em: 20 nov. 2016.

MATTOS, C. \& YOUNG, C. P. Colonização agrícola em floresta tropical úmida e seus impactos ambientais: o caso de Machadinho d'Oeste - Rondônia. Campinas: Embrapa Monitoramento por Satélite, 1991. MMA - Ministério do Meio Ambiente. Sistema nacional de unidades de conservação SNUC: Lei $\mathrm{n}^{\circ}$ 9.985, de 18 de julho de 2000; decreto $\mathrm{n}^{\circ} 4.340$, de 22 de agosto de 2002. Brasília, 2004. 
MIRANDA, E. E.; MANGABEIRA, J. A. C.; MATTOS, C.; DORADO, A. J. Perfil agroecológico e sócio-econômico de pequenos produtores rurais: o caso de Machadinho d'Oeste (RO), em 1996. Campinas: ECOFORÇA/Embrapa-NMA, 1997. 117 p. (Documentos, 2).

QUADROS, M.L.E.S. Geologia e recursos minerais da Folha Rio Machadinho (SC.20X-C): Sistema de Informações Geográficas - SIG. Porto Velho: CPRM, 2011. QUADROS, M.L.E.S.; RIZZOTTO, G.J. (organizadores). Mapa geológico e de recursos minerais do estado de Rondônia. Escala 1:1.000.000, Porto Velho, CPRM, 2007.

RIBEIRO, B.; VERÍSSIMO, A.; PEREIRA, K. O avanço do desmatamento sobre as Áreas Protegidas em Rondônia. IMAZON, 2005. Disponível em: <http:// http://www.imazon.org.br/PDFimazon/Portugues/estado_da_amazonia/o-avanco-dodesmatamento-sobre-as-areas-protegidas.pdf >. Acesso em: 26 jul. 2016. RONDÔNIA. Atlas geoambiental de Rondônia. Porto Velho, SEDAM, 2002. SAWYER, D. Evolução demográfica, qualidade de vida e desmatamento na Amazônia. In: Causas e dinâmica do desmatamento da Amazônia, Brasília: MMA, 2001. 